\title{
Use of Drilling Muds for Remediation
}

\author{
Yulia Galitskova ${ }^{1, *}$ \\ ${ }^{1}$ Samara State Technical University, Institute of Architecture and Civil Engineering, \\ 194,Molodogvardeyskaya St., 443001, Samara, Russia.
}

\begin{abstract}
Drilling wells is an ecologically dangerous type of work accompanied by contamination of soil, subsurface and surface waters, pollution of open air with drilling and technological wastes. Throughout the drilling process, drilling waste is generated, such as drilling muds, return drilling muds, drilling waste water. The resulting waste is usually disposed of at landfills, which ensure minimal environmental impact. The use of drilling muds in other spheres is hindered by the complex composition of oily waste. Samples of liquids and solids in drilling wastes, picked at three locations, were subjects for analysis. The waste sample was analyzed for moisture content, organic substances, oil products, silicon, iron and other substances. Based on the studies performed, the authors propose additional introduction of substances possessing high sorption capacity into drilling mud to improve its properties. The most effective way should be using a sorbent capable of retaining organic and heavy metals. The resultant homogeneous soil-like mixture possesses the necessary and sufficient properties to be used as a mineral base for remediation after performing construction work in urban areas.
\end{abstract}

\section{Introduction}

Despite the high environmental threats associated with drilling operation, the negative impact of the generated drilling wastes, as well as the minimum amount of the waste treatment, we observe the widespread expansion of the territories where drilling is performed. A lot of scientists are engaged in research on waste treatment, various methods for the recovery of drilling wastes are being developed [1-5]. Utilizing wastes in other spheres, e.g. for production of building materials, is being studied as well [6-9]. However, in most cases, the process is associated with the need for specialized stationary equipment, which increases the cost of transporting drilling muds from remote wells.

Today, large oil companies store drilling muds at cluster pads [10-11], research various additives and reagents allowing the drilling muds to be converted into fuel, fertilizers or construction soil. The utilization of such material is possible provided it is not contaminated [12].

Drilling muds can be stored temporarily in the waste pit on the drilling site (Figure 1), which also has a negative impact on the environment.

\footnotetext{
*Corresponding author: galickova@yandex.ru
} 


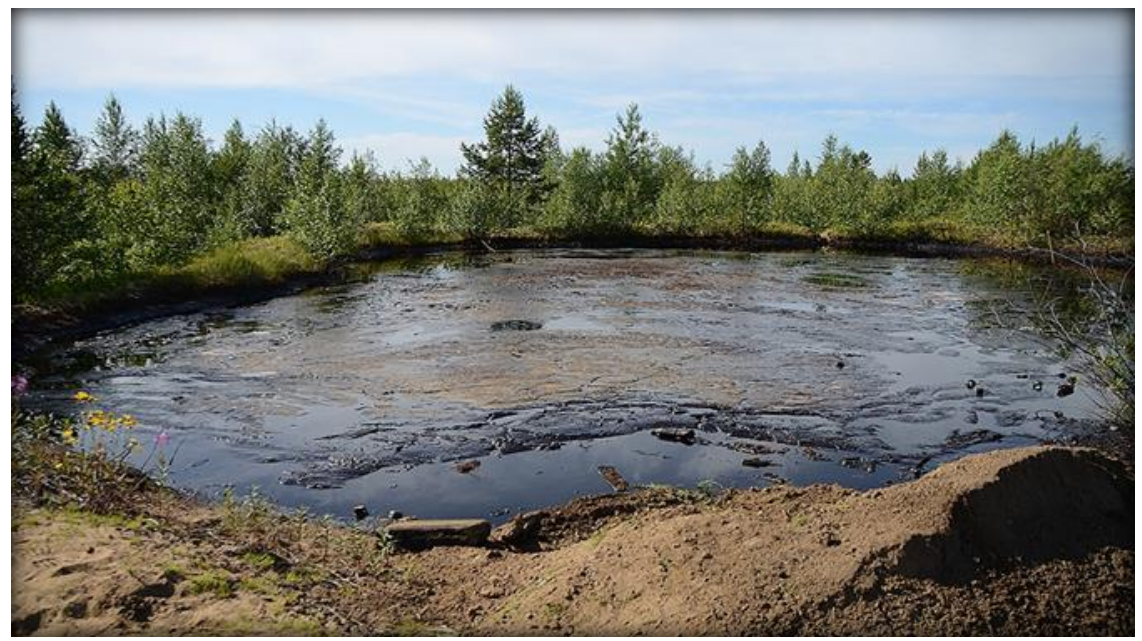

Fig. 1. Mud pit.

Mud pits with toxic drilling muds render large territories unusable, and after the well is operated and then abandoned, the pit is subject to decommissioning. It should be noted that a simple back-filling of a pit is not acceptable, since drilling wastes inhibit soil enzymatic processes, reduce the biological activity of living microorganisms, and also reduce the fertility of soils.

\section{Materials and Methods}

Within the scientific work, University representatives conducted research on the composition of drilling muds from the Novokrasinsky and Eruslan deposits of the Volgograd region, Tsarichansko-Filatovsky, Novosergievsky and Perevolotsky deposits in the Orenburg region. The formation of these deposits are characterized by the complexity of their development and low permeability. For such a complicated oil extraction, high-tech drilling with multi-stage hydrofrac is applied. There are intervals in which the drilling muds begin to leak into the formation, up to the point that it ceases to reach the surface. At great depths, the walls of the well lose their strength and collapse.

The wells in question belong to the deviated type with flat dipping. Target well depths range from 4260 to $4414 \mathrm{~m}$. Target horizon - Kolgan section.

The main wastes generated during the drilling process will be drilling muds, return muds, drilling waste water. Production well sites provide a single-section tank with an additional pit for accumulation of drilling wastes.

The composition of a drilling mud can be very diverse depending on the geological conditions, applied drilling fluids, drilling technology. In the cases under consideration, clay fluid based on service water with the addition of salt-saturated elements is used.

To determine the physical and chemical composition properties, we considered the samples of liquids and solids of drilling wastes picked from 3 locations:

1. Vibrating screen. Measurement of the parameters of the return muds leaving the well should be carried out as close to the well head as possible, preferably before contact with the atmosphere. Such a place is a receiving tank of the vibrating screen. The sampling location is shown in Figure 2 (left).

2. Mud pit, the place where solids settle. To measure the parameters of the waste taken out to the surface, a part of the mud is collected in the amount necessary for the study. The sampling location is shown in Figure 2 (right). 


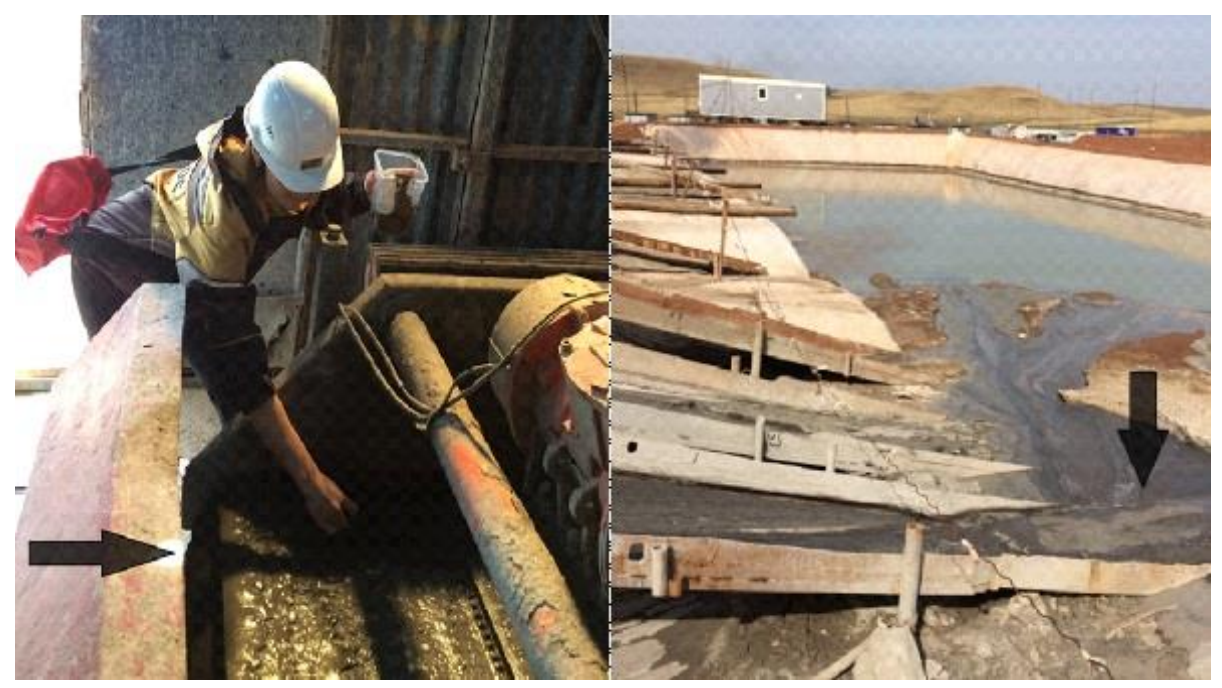

Fig. 2. Sampling locations: left - №1, right - №2.

3. Mud pit, the place where liquids settle. Drilling wastewater generated on the vibrating screens during washing of the rock extracted from the well, cooling of the drilling pumps, and the removal of the drilling muds spilled during the tripping operations are accumulated and settled in the upper level of the mud pit (Figure 3).

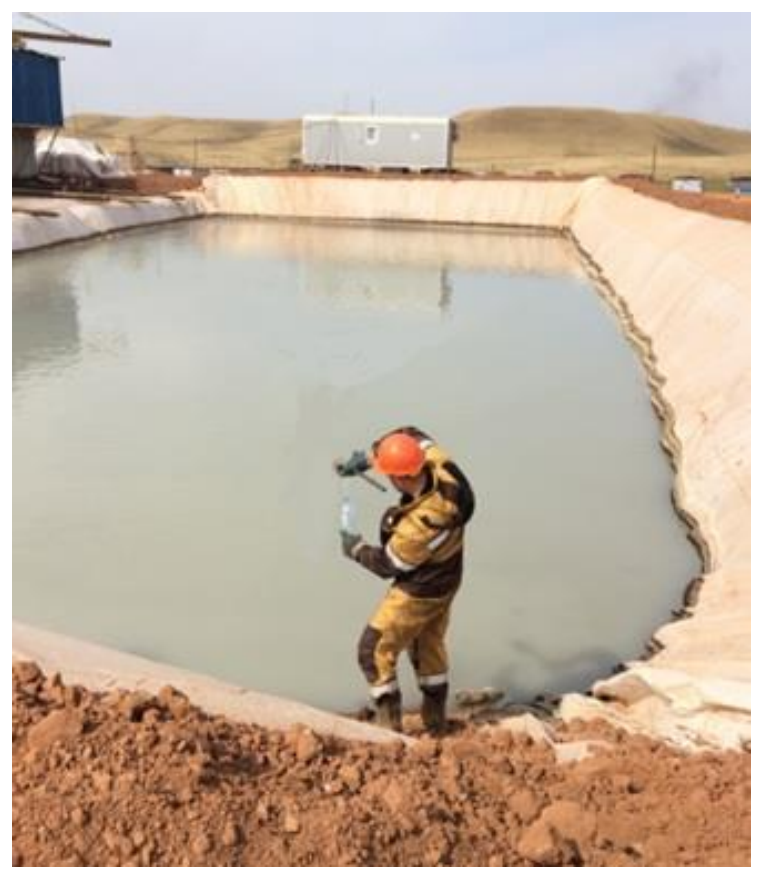

Fig. 3. Sampling at location №3.

Samples were examined in a licensed laboratory. The sample of waste (Figure 4) was analyzed for moisture content, organic substances, petroleum products, silicon, iron, aluminum, calcium, magnesium, sodium, potassium, sulfate ions, carbonate ions. 

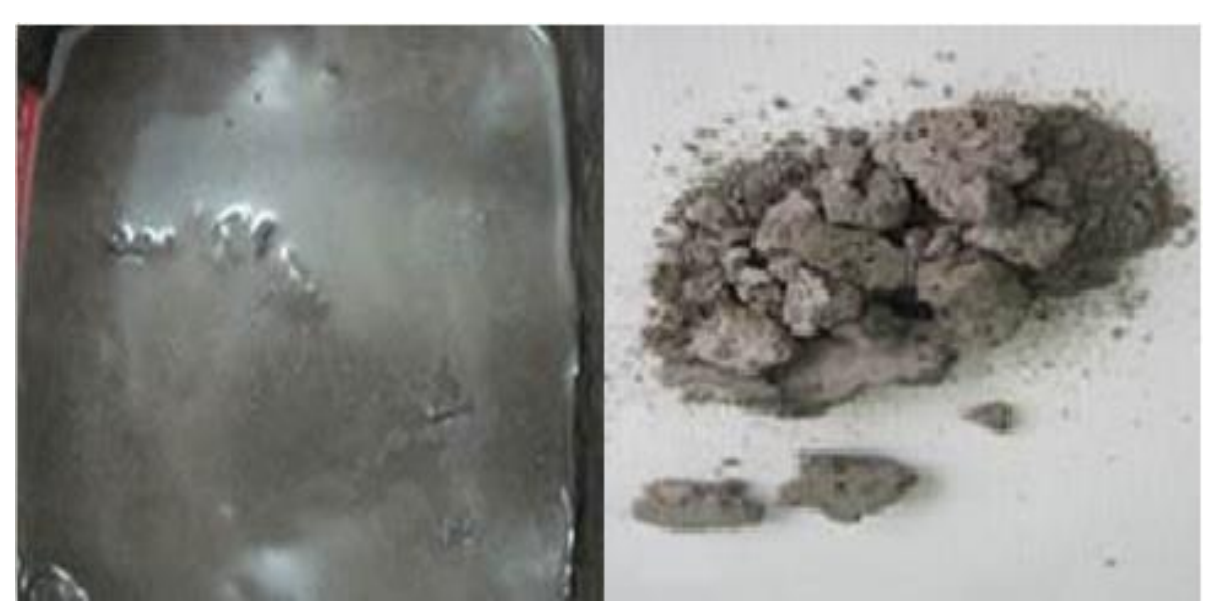

Fig. 4. Sample:

left - prior to analysis, right - after dewatering and dissolving of other components soluble in organic solvents.

Based on the results of quantitative chemical analysis, the waste component composition was calculated.

\section{Results}

The results of the chemical analysis and the average value of the drilling mud component composition are presented in Tables 1-3.

Table 1. Results of quantitative chemical analysis of drilling mud picked at location 1.

\begin{tabular}{|c|c|c|}
\hline Components & Contents, $\mathrm{mg} / \mathrm{kg}$ & $\begin{array}{c}\text { Measured values, } \\
\% \text { of total mass }\end{array}$ \\
\hline Moisture content & 780800 & 78.08 \\
\hline Petroleum products & 1000 & 0.10 \\
\hline Clay & 70100 & 7.01 \\
\hline Calcium chloride & 31200 & 3.12 \\
\hline Magnesium chloride & 28700 & 2.87 \\
\hline Calcium sulphate & 400 & 0.04 \\
\hline Calcium carbonate & 49800 & 4.98 \\
\hline Magnesium carbonate & 5600 & 0.56 \\
\hline Ferrous oxide & 32400 & 3.24 \\
\hline
\end{tabular}

Table 2. Results of quantitative chemical analysis of drilling mud picked at location 2.

\begin{tabular}{|c|c|c|}
\hline Components & Contents, $\mathrm{mg} / \mathrm{kg}$ & $\begin{array}{c}\text { Measured values, } \\
\% \text { of total mass }\end{array}$ \\
\hline Moisture content & 637700 & 63.77 \\
\hline Petroleum products & 1300 & 0.13 \\
\hline Clay & 103700 & 10.37 \\
\hline Calcium chloride & 42600 & 4.26 \\
\hline Magnesium chloride & 35900 & 3.59 \\
\hline Calcium sulphate & 3200 & 0.32 \\
\hline
\end{tabular}




\begin{tabular}{|c|c|c|}
\hline Calcium carbonate & 71800 & 7.18 \\
\hline Magnesium carbonate & 56700 & 5.67 \\
\hline Ferrous oxide & 32400 & 3.24 \\
\hline
\end{tabular}

Table 3. Results of quantitative chemical analysis of drilling mud picked at location 3.

\begin{tabular}{|c|c|c|}
\hline Components & Contents, $\mathrm{mg} / \mathrm{kg}$ & $\begin{array}{c}\text { Measured values, } \\
\% \text { of total mass }\end{array}$ \\
\hline Moisture content & 980600 & 98.06 \\
\hline Clay & 19400 & 1.94 \\
\hline
\end{tabular}

Additionally, based on the results of chemical analysis of each type of waste, a waste hazard rating was calculated, in accordance with the requirements of the regulatory and methodological documentation. All studied drilling wastes were classified as belonging to the hazard class IV (wastes rated as low-hazardous for the environment).

Based on the above, we can conclude that the resulting drilling mud that has undergone a four-stage purification can be used as feedstock for processing into the hazard class $\mathrm{V}$ waste or for final decontamination.

\section{Discussion}

As noted above, one of the ways to improve the drilling mud properties, when it does not adversely affect the environment, is the introduction of substances with high sorption abilities.

There exist several sorbents used for neutralization of drilling muds. The comparative analysis of sorbent groups has shown that the most effective should be the Sorbentdestructor, which includes carbon and silicon dioxide as the most natural elements for the soil. That is, the sorbent should exhibit the properties of coals and silicate adsorbents, provide fixation of organic substances and heavy metals, both on the surface and in the absorber, by creating chemical and physical bonds with the active sorbent groups.

Sorbent-destructor СД-1 acts as the most suitable and adequate for the necessary requirements [6]. It does not include artificial biodestructing microorganisms, and its oxidative activity is determined by the fact that it is a highly effective incubator for the local natural community of biodestructing microorganisms.

As a result of using this sorbent, it is possible to obtain a finished product in the form of a homogeneous soil-like mixture.

We recommend processing drilling muds into the soil directly in the mud pits. To do so, the design solutions for the construction of a mud pit are analyzed during the preparatory stage to determine the feasibility of using this processing technology.

Within the technological stage, we recommend creating zones in the pit where mixing of drilling mud with the reagent takes place. At the end of the drilling waste processing stage, intermediate monitoring of the obtained soil is carried out.

At the biological stage, a 10-20 cm fertile layer is created on the remediated surface.

\section{Conclusions}

To minimize the negative impact of drilling wastes on the environment, as well as to reduce the amount of drilling muds that are disposed of on special sites, the compositions of drilling muds formed at several drilling sites were analyzed. Based on the results of the research, the authors proposed to use a sorbent that allows not only to decontaminate 
drilling muds and decrease their hazardousness from class 4 to class 5, but also to obtain an artificial soil that does not exhibit hazardous characteristics.

The obtained mixture can serve as a mineral base for the fertile layer at the stage of biological reclamation, be used in the road surface dressing of field roads and field sites instead of imported rock materials, during construction, reconstruction and repair, and also at the production and supporting facilities of oil and gas deposits for filling pits, trenches and for other types of work where traditional soils are used.

Alternatively, the absence of contaminators allows the use of such artificial soil in the planning of construction sites of urban settlements, as well as in land improvement.

The economic effect of using the sorbent (calculating the data for one well) amounts to about 5 million rubles.

\section{References}

1. J. Järnegren, S. Brooke, H. Jensen, Deep-Sea Research Part II: Topical Studies in Oceanography 137, 8 (2017)

2. I.P. Junior, A.L. Martins, C.H. Ataide, C.R. Duarte, Bulletin of the Institute of Journal of Environmental Management 196, 6 (2017)

3. A.I. Murzayeva, Y.M. Galitskova, Procedia Engineering 153, 4 (2016)

4. R.A. Savinov, A.V. Kalashnikov, D.A. Konuhov, A.V. Petrov, Environmental protection in oil and gas complex 8, 2 (2011)

5. A.A. Annenkov, V.A. Grabovnikov, N.N. Egorov, Exploration and protection of mineral resources 10, 4 (2013)

6. I.A. Bobrenko, E.U. Pavlova, Omsk scientific Bulletin 1, 4 (2015)

7. N.V. Stolbova, A.A . Matsuk, E.A. Shafeeva, Science and technology in gas industry 1,3 (2015).

8. V. A. Gureva, V.V. Dubinetsky, K.M. Vdovin, Building materials 4, 2 (2015)

9. E. A. Pichugin, B.E. Schonfeld, Ecology and industry of Russia 12, 3 (2015)

10. N. L. Sienko, E.A. Timofeeva, Bulletin of Perm national research Polytechnic University. Construction and architecture 1, 13 (2015)

11. O.V. Zueva, V.U. Zaripov, V.I. Hook, I.A. Freiberg, Agricultural education and science 4, 52 (2016)

12. E.V. Kim, O.V. Andreev, V.Yu. Ryadinskiy, Herald of Tyumen state University. Ecology and natural resource management 3, 4 (2010) 